\title{
Evaluating European LIFE conservation projects: Improvements in survival of an endangered vulture
}

\author{
Jaume Adrià Badia-Boher ${ }^{1,2,3}$ | Ana Sanz-Aguilar ${ }^{1}$ (i) | Manuel de la Riva ${ }^{2}$ | \\ Laura Gangoso $^{2,4}$ | Thijs van Overveld ${ }^{2}$ | Marina García-Alfonso² | \\ Octavio P. Luzardo ${ }^{5,6}$ | Alejandro Suarez-Pérez ${ }^{7}$ José Antonio Donázar ${ }^{2}$
}

\begin{abstract}
${ }^{1}$ Animal Demography and Ecology Unit, IMEDEA (CSIC-UIB), Esporles, Spain; ${ }^{2}$ Estación Biológica de Doñana, Sevilla, Spain; ${ }^{3}$ Department of Biology, Lund University, Lund, Sweden; ${ }^{4}$ Institute for Biodiversity and Ecosystem Dynamics (IBED), University of Amsterdam, Amsterdam, The Netherlands; ${ }^{5}$ Toxicology Unit, IUIBS, Las Palmas de Gran Canaria University, Las Palmas de Gran Canaria, Spain; ${ }^{6}$ Spanish Biomedical Research Center in Physiopathology of Obesity and Nutrition (CIBERObn), Madrid, Spain and ${ }^{7}$ Animal-Lab S.L., Las Palmas de Gran Canaria, Spain
\end{abstract}

Correspondence

Ana Sanz-Aguilar

Email: asanz@imedea.uib-csic.es

\section{Funding information}

Spanish Ministry of Economy and Competitiveness and EU/FEDER, Grant/

Award Number: REN 2000-1556 GLO,

CGL2004-00270/BOS, CGL2009-

12753-C02-02, CGL2012-40013-C02-01

and CGL2015-66966-C2-1-2-R; Lund

University; Govern Balear and European

Social Funds Vicenç Mut, Grant/Award

Number: PD/003/2016; Marie Sklodowska-

Curie Fellowships; Programa de FPU, Grant/

Award Number: FPU13/05429; Dirección

General de Protección de la Naturaleza;

Cabildos Insulares de Fuerteventura and

Lanzarote; Reserva de la Biosfera de

Fuerteventura; Jerez Zoo; ENDESA

Handling Editor: Ayesha Tulloch

\section{Abstract}

1. Long-lived avian scavengers are threatened worldwide and thus, are common targets of conservation plans. However, scientific evidence of both the factors limiting populations and effectiveness of management actions are greatly needed in order to develop more efficient and successful conservation strategies.

2. We assessed the effectiveness of conservation actions applied within a LIFENature project aimed at improving the long-term survival of the critically endangered Canarian Egyptian vulture: including education campaigns for public awareness and control of illegal poisoning and the modification of power lines to reduce the risk of accidents. We formulated a multievent capture-mark-recapture model to obtain estimates of survival for juvenile, subadult and adult birds accounting for probabilities of resight, recovery and losses of metal and colour rings.

3. Models supported a substantial enhancement in survival for subadult and adult birds and a moderate improvement for juveniles after the implementation of LIFE actions. Ring loss probabilities became notably high in the middle to long term.

4. Poisoning events became very rare after LIFE was implemented, suggesting a positive effect of environmental education and awareness campaigns. Entanglements and collisions in power lines were also efficiently mitigated. Instead, electrocutions became the most identified cause of death in the post-LIFE stage.

5. Synthesis and applications. Our results highlight the improvement of survival in a threatened island vulture population after the implementation of a European LIFE conservation project. On small islands, with small human populations and few stakeholders, education and awareness campaigns can be especially effective for biodiversity conservation. We also demonstrate the need to complement conservation programmes with long-term monitoring, which is essential to evaluate the effectiveness of actions, especially for long-lived species. 


\section{KEYWORDS}

capture-recapture, conservation programme success, Egyptian vulture, environmental education, long-term monitoring, mortality, poisoning, ring loss

\section{1 | INTRODUCTION}

Studies identifying threats and assessing the effectiveness of management measures for species, populations and ecosystems are essential for the conservation of biodiversity (Ferraro \& Pattanayak, 2006; Frederiksen, Lebreton, Pradel, Choquet, \& Gimenez, 2014; Sutherland, Pullin, Dolman, \& Knight, 2004). Systematic long-term evaluation helps pinpointing the effectiveness of management strategies and enhances discussions on how to improve them (Rose et al., 2018; Sutherland et al., 2004). The LIFE Programme is the main funding instrument for nature conservation in the European Union (EU). One of its key objectives is to achieve the EU 2020 Biodiversity target of ceasing biodiversity loss (European Commission, 2011). However, after substantial economic and institutional efforts, the conservation status of only a few target species and habitats has improved, whereas many are still impoverished or declining. This has led to concerns about the programme's overall effectiveness (European Environmental Agency, 2010, 2011; Hermoso, Clavero, Villero, \& Brotons, 2017).

Adding evidence-based conservation strategies, by means of systematically assessing the effectiveness of specific LIFE actions on targeted species and habitats, could be essential in order to improve the overall results of this programme (Henle et al., 2013; Rose et al., 2018). However, as for most management actions worldwide, LIFE actions are not always robustly evaluated (Henle et al., 2013; Hermoso et al., 2017; Pullin, Knight, Stone, \& Charman, 2004). This is particularly true for long-lived vertebrate species, which are usually priority targets of conservation funding, including many LIFE projects (Cardoso, Erwin, Borges, \& New, 2011; Hermoso et al., 2017). Survival of adult, and to a lesser extent, subadult individuals, is the key parameter influencing population viability and dynamics of long-lived species with deferred sexual maturity (Saether \& Bakke, 2000; Sergio et al., 2011). However, long-term monitoring programmes are required to obtain robust survival estimates (SanzAguilar et al., 2017). Long-lived species show age-structured patterns of survival, which generally increases with age as a result of age-related improvements in several skills (e.g. foraging, territory acquisition, migration, reproduction, etc.) or due to the selective disappearance of low quality individuals during early life (McNamara \& Houston, 1996; Sergio et al., 2014). Consequently, it is essential to establish appropriate long-term evaluations on how conservation measures affect key demographic parameters (i.e. survival) in these species (Kelly et al., 2015; Lieury, Gallardo, Ponchon, Besnard, \& Millon, 2015; Oro, Margalida, Carrete, Heredia, \& Donázar, 2008; Sanz-Aguilar, Martínez-Abraín, Tavecchia, Mínguez, \& Oro, 2009).

Large avian scavengers (i.e. condors and vultures) are very long-lived species, with some individuals living over 40 years (De
Magalhães \& Costa, 2009). Vultures are experiencing dramatic population declines throughout the world, to the extent that nowadays they are among the most threatened animal taxa (Birdlife International, 2018; Ogada, Keesing, \& Virani, 2012). The main reasons for their declines are mortality by poisoning (intentional or unintentional) and accidents with man-made structures (Botha et al., 2017). In these species, age-related behavioural changes (e.g. territoriality, changes in foraging strategies) can have substantial impacts in their chances of mortality by anthropogenic factors (Hernández \& Margalida, 2009). Adults are more susceptible to illegal poisoning than juveniles and subadults, which typically rely more on supplementary feeding stations (Hernández \& Margalida, 2009). On the other hand, subadults can be especially vulnerable to accidents with man-made structures during the pre-breeding period, in which individuals prospect potential territories (Grande et al., 2009; Graiger Hunt et al., 2017). In such a context, estimating age-related survival rates of threatened populations is essential to design efficient management actions and to test for their effectiveness (Morris \& Doak, 2002).

Capture-mark-recapture (CMR) models can be especially useful to estimate the age- or stage-dependent survival probabilities while accounting for imperfect detection of individuals (Lebreton, Burnham, Clobert, \& Anderson, 1992). However, CMR studies rely on several critical assumptions, such as the fact that marks are not lost (Williams, Nichols, \& Conroy, 2002). When dealing with long-lived species through long-term studies, marks can deteriorate and become lost, preventing individual identification (Jovani \& Tella, 2005) and robust estimation of demographic parameters. Developments in CMR models during the last few decades allow the robust estimation of survival while accounting for mark loss (e.g. Cowen \& Schwarz, 2006; Nichols \& Hines, 1993; Sanz-Aguilar, De Pablo, \& Donázar, 2015).

The Egyptian vulture (Neophron percnopterus) is a globally endangered, widely distributed long-lived scavenger species (Birdlife International, 2017). The Canarian non-migratory subspecies (Neophron percnopterus majorensis) was widespread across the archipelago in the early 20th century, but is now restricted to the easternmost islands: Fuerteventura and Lanzarote (Spain; Martín, 1987). Local extinctions and a dramatic population decline in the last half of the 20th century has led this subspecies to be listed as "Critically Endangered" (Palacios, 2004), with a global population limited to 21 territories as of 1998 (unpublished data). Casualties due to power lines and illegal poisoning were identified as the main causes of mortality, with shootings, ingestion of lead bullets and natural causes contributing to a lesser extent (Donázar et al., 2002; Gangoso \& Palacios, 2002; Gangoso et al., 2009). Between 2004 and 2008, a LIFE-Nature Project (LIFE04NAT/E/000067) was implemented to 
mitigate non-natural mortality in this population. Specifically, LIFE management actions were focused on (a) the modification of power lines with anti-collision and anti-entanglement systems (performed during 2005) and (b) the implementation of awareness-raising and environmental education campaigns to educate the public about the deleterious effects of illegal poisoning.

Here, we assess the effectiveness of these LIFE actions, taking advantage of a long-term monitoring programme (1998-2017) in which over $90 \%$ of the population had been individually ringed by 2017. We designed and applied a state-of-the-art multievent CMR framework (Pradel, 2005) to estimate the survival of juvenile, subadult and adult birds before and after the implementation of LIFE management actions, while accounting for the loss of two different kinds of rings used simultaneously during the study. In addition, we collected and analysed data on the causes of mortality of marked and unmarked dead individuals recovered during the 20-year study period. If conservation measures were successful, we would predict a reduction in the incidence of anthropogenic causes of mortality (casualties due to power lines and poisoning), which, in turn, would result in enhanced survival for all age classes. Our specific objectives were to (a) assess whether survival improved after the implementation of LIFE measures and (b) evaluate changes in the causes of mortality after LIFE actions. Finally, we aimed to provide estimates of ring loss, recovery and resighting probabilities.

\section{2 | MATERIALS AND METHODS}

\subsection{Study area and population monitoring}

The long-term intensive monitoring of the species on Fuerteventura and Lanzarote islands began in 1998. Between 1998 and 2017, 369 fledglings were captured in their nests (age $~ 35-65$ days old, from mid-May to early August). In addition, eight juvenile (1-year-old), 66 subadult (2- to 5 -years old) and 44 adult ( $\geq 6$-years-old) birds were captured using cannon-nets baited with carcasses. Their age was reliably assessed until their fifth year according to plumage patterns (Forsman, 2016). All captured individuals were marked with metal and plastic colour-rings with unique alphanumeric codes. The codes on the colour-rings can be identified from up to $300 \mathrm{~m}$, while the codes on the metal rings required considerably closer distances. During the monitoring period, we noticed that some individuals had lost their plastic or metal butt-end rings. Hence, we took advantage of cannon-net capture sessions to replace the missing rings. In addition, from 2015 onwards, we marked all newly ringed and all recaptured individuals with metal lock-on rings instead of metal butt-end rings, as lock-on rings are expected to be permanent.

Breeding territories, supplementary feeding stations and communal roosts were intensively monitored each year from February to August to resight marked individuals. Observations from 1998 to 2017 ( $n=3,308$ live resightings/recaptures and 63 freshly recovered carcasses) were encoded in annual capture-recapture histories. Moreover, we recovered 25 carcasses of unmarked individuals. Carcasses were found during regular monitoring (including systematic searches under power lines) and, on a non-systematic basis, following indications by locals, tourists and government personnel. The causes of death were determined when possible through necropsy in wildlife rehabilitation centres and veterinary facilities. According to the diagnostic results, individuals were assigned to one of six death causes: (a) poisoning by toxic baits, including secondary poisonings ( $n=24$ ); casualties with power lines either due to (b) electrocution ( $n=15)$, (c) collision $(n=5)$ or (d) entanglement $(n=7)$; (e) other causes, including apparent natural mortality such as infections or malnutrition as well as shooting and lead poisoning $(n=7)$; or ( $f$ ) unknown causes $(n=30)$. We assigned causes of mortality of marked and unmarked juveniles, subadults and adults before and after the LIFE project measures.

\section{2 | Survival modelling}

We developed a multievent CMR model (Pradel, 2005) to estimate the probabilities of survival of multiple age classes, resight/recapture of live individuals, recovery of dead individuals and ring loss (see Appendix S1). Individuals were aged during ringing (see above). We checked for possible sources of heterogeneity in survival and recapture (Pradel, Gimenez, \& Lebreton, 2005) using the goodness-of-fit GOF tests for the Jolly Movement multistate model (which assumes that all parameters are time and state-dependent), available in the software U-CARE 2.3.2 (Choquet, Lebreton, Gimenez, Reboulet, \& Pradel, 2009).

The Multievent model was implemented in the software ESURGE (Choquet, Rouan, \& Pradel, 2009). Parameters of interest were estimated simultaneously by maximum likelihood (Choquet, Rouan, et al., 2009). Our starting general model included: (a) a linear effect of time since ringing on ring loss probabilities, because rings can deteriorate over time; (b) temporal additive variation in survival of juveniles, subadults and adults, since factors affecting vulture mortality may have changed during the whole study period; (c) temporal additive variation in resighting probabilities of birds carrying colour-rings and birds carrying only metal rings, because identifying the code of a colour-ring is easier than reading a metal ring, and the monitoring effort or efficiency may have changed between years; and (d) temporal variation in recovery probabilities, because the monitoring effort or efficiency may have changed between years. Model selection was based on Akaike's information criterion adjusted for small sample sizes (AIC, Burnham \& Anderson, 2002). Models with a $\Delta \mathrm{AIC}_{c} \leq 2$ were considered equivalent (Burnham \& Anderson, 2002). The Akaike's weight $\left(w_{\mathrm{i}}\right)$ was calculated as an index of relative model plausibility and used to obtain model averaged estimates (Burnham $\&$ Anderson, 2002). We performed a stepwise model selection procedure (see details in Appendix S1). We first tested for temporal effects on recovery and resight probabilities. We then tested the effect of time since ringing (i.e. ring age) on ring loss probabilities using logarithmic and constant models. Finally, once the best model structure for resight, recovery and ring loss parameters was selected (i.e. the effects that minimized $\mathrm{AIC}_{c}$ ), we evaluated the effect of the LIFE project management measures on survival probabilities. 
FIGURE 1 Average estimates (and 95\% Cl) of yearly resight probabilities of Canarian Egyptian vultures marked with colour-rings (squares) and metal rings (circles)

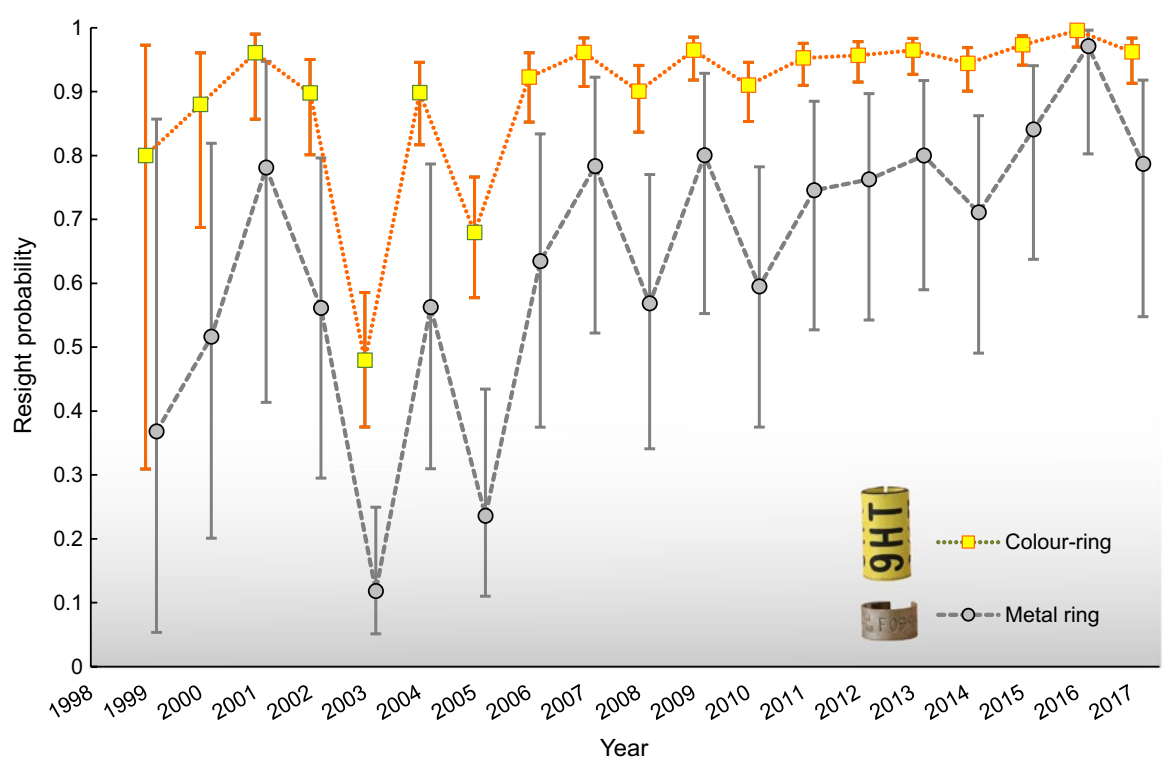

The LIFE project awareness campaigns were conducted during the whole project but modification of power lines was implemented in 2005 (see Appendix S2). Consequently, we considered the middle of the project as the reference point for evaluation (before LIFE, 1998-2006; after LIFE, 2007-2017). We tested if changes on survival occurred after 2006 and if this changes were proportional (i.e. additive) or differential (i.e. interaction) for juveniles, subadults and adult birds. Moreover, in order to assess the robustness of the LIFE project effect to the reference point considered we performed additional models with immediate effect (reference point at 2004) and after-termination effect (reference point at 2008) of the LIFE project effects (see details in Appendix S1).

\section{3 | RESULTS}

The global goodness-of-fit test model indicated an adequate fit to the data $\left(\chi^{2}=34.97, d f=88, p=1\right)$. Resight probabilities were very high (especially for birds carrying colour-rings) and varied over time (Figure 1) but independently of recovery probabilities. Models considering either constant or temporal probabilities of recovery (i.e. probabilities of finding the carcasses of dead vultures) were equally supported in terms of $\mathrm{AIC}_{c}$ (see Appendix S1: Table SA1.2). The mean probability of carcass recovery was estimated at $0.34(95 \%$ Cl 0.27-0.41).

For ring loss probabilities, the models that minimized the $\mathrm{AIC}_{c}$ (see Appendix S1: Tables SA1.3 and SA1.4) indicated that the probabilities of losing both types of rings varied as logarithmic functions of the time since ringing (see Appendix S1: Table SA1.2, Figure 2). Colour-ring loss probabilities were very low during the first 5-6 years of use but increased progressively as the ring became older (Figure 2). In comparison, metal buttend rings showed higher loss probabilities during the first years, which kept increasing at a slower pace throughout the years
(Figure 2). Cumulative probabilities of band loss showed that from 10 years after ringing onward a substantial proportion of ringed animals are expected to have lost at least one of their rings (Figure 2).

Models considering changes in survival after the LIFE Project implementation considering 2006 as reference point were robustly supported in terms of AIC $_{c}$ (Appendix S1: Table SA1.5). Model averaged estimates of survival showed a clear improvement of adult $\left(\phi_{\text {before }}=0.89,95 \% \mathrm{Cl} 0.84-0.92 ; \phi_{\text {after }}=0.93,95 \%\right.$ $\mathrm{Cl} 0.91-0.95)$ and subadult survival $\left(\phi_{\text {before }}=0.90,95 \% \mathrm{Cl} 0.87-\right.$ $\left.0.93 ; \phi_{\text {after }}=0.95,95 \% \mathrm{Cl} 0.94-0.96\right)$, which relatively increased $4.8 \%$ and $5.0 \%$, respectively (Figure 3 ). A slightly lower relative improvement (3.5\%) was found for juveniles, in which the $95 \%$ $\mathrm{Cl}$ of survival estimates before $(\phi=0.92,95 \% \mathrm{Cl} 0.86-0.95)$ and after $(\phi=0.95,95 \% \mathrm{Cl} 0.92-0.97)$ the LIFE project greatly overlapped (Figure 3). Model selection indicated that the improvement of survival occurred during the implementation of LIFE project measures (in year 2006), not at the start of the project (year 2004) or after its total implementation (year 2008; see details in Appendix S1).

Mortality data indicate the existence of substantial differences in the proportion of individuals found dead by different mortality causes before and after the LIFE project implementation (Table 1). Before the LIFE actions, poisoning-especially of adults-was the most frequent cause of death (Table 1). Casualties with power lines as a whole were the second most reported cause of mortality, mainly due to entanglement, followed by collision and then electrocution. The observed proportion of each mortality cause markedly changed after the implementation of LIFE measures (Table 1). Only three cases of poisoning were detected, accounting for a minor proportion of mortality causes. Collisions and entanglements in power lines were no longer detected. Instead, electrocution became the sole cause of mortality reported due to these structures. 


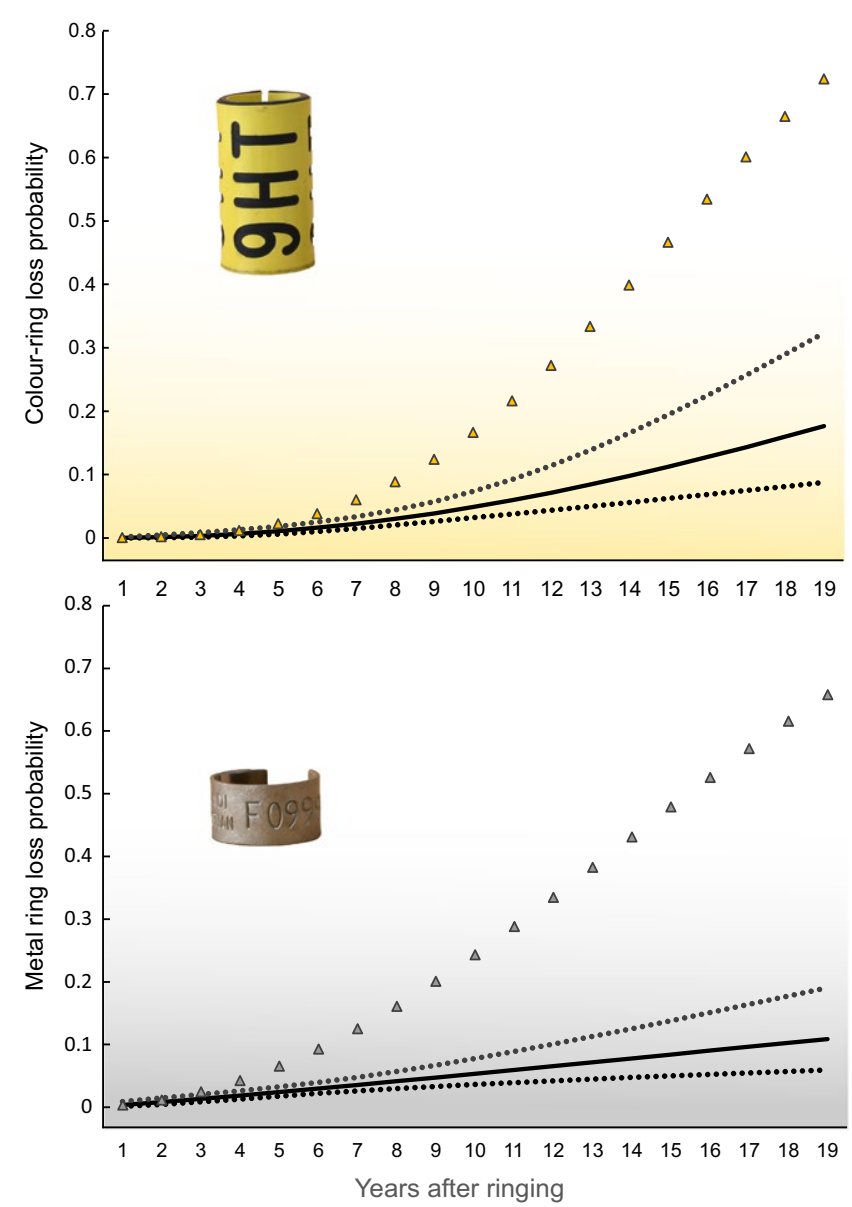

FIGURE 2 Estimates of yearly (solid line) and cumulative (triangles) ring loss probabilities depending on the number of years elapsed after ringing. Dotted lines represent $95 \% \mathrm{Cl}$ for yearly ring loss probabilities

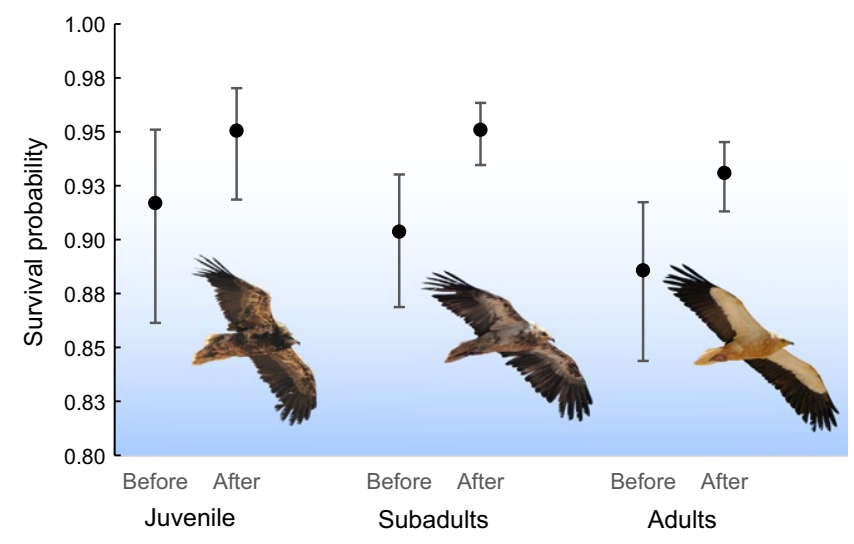

FIGURE 3 Averaged estimates (and 95\% Cl) of juvenile, subadult and adult survival probabilities of Canarian Egyptian vultures before (1998-2006) and after the implementation of LIFE management measures (2007-2017)

\section{4 | DISCUSSION}

Monitoring endangered populations is essential for identifying threats and planning conservation actions. The Canarian Egyptian vulture population has been intensively monitored over the last 20 years, allowing the detection of mortality causes (Donázar et al., 2002; Gangoso \& Palacios, 2002), the planning and implementation of conservation actions (LIFE04NAT/E/000067) and the evaluation of their outcomes (this study). Our results provide strong evidence for a positive correlation between the implementation of the LIFE project measures and the improvement of survival of a highly threatened species. Survival improved for all age classes, especially for subadults and adults. After LIFE actions, all age classes showed high survival prospects: $95 \%$ for juveniles and subadults and $93 \%$ for adults. This adult survival estimate is similar to other stable Egyptian vulture populations in France (Lieury et al., 2015) and the Balearic Islands (Sanz-Aguilar, De Pablo, et al., 2015) and higher than those estimated for threatened Spanish populations in the Ebro Valley and Andalusia (Sanz-Aguilar et al., 2017; Sanz-Aguilar, Sánchez-Zapata, et al., 2015) and for the Balkan populations (Oppel et al., 2016). Population viability in long-lived species is highly dependent on adult survival (Saether \& Bakke, 2000). In fact, in parallel with the survival improvements that occurred after the LIFE project, the population approximately tripled, shifting from 21 territories in 1998 to 67 in 2017 (unpublished data). A minor survival increase was detected for juveniles. Interestingly, juvenile survival was relatively high during the entire study period and was very similar to subadult and adult survival, similarly to the patterns described for other non-migratory raptor populations inhabiting island systems (Sanz-Aguilar, De Pablo, et al., 2015). In fact, migration and wintering conditions are important determinants of juvenile mortality in avian trans-Saharan migratory species (Grande et al., 2009; Klaassen et al., 2014).

Juveniles typically forage on predictable and poison-free food resources available in supplementary feeding stations (Hernández \& Margalida, 2009; Oro et al., 2008). On the contrary, adults, due to their territorial habits, are more susceptible to poisoning (Cortés-Avizanda, Colomer, Margalida, Ceballos, \& Donázar, 2015; Hernández \& Margalida, 2009). Therefore, improvements in adult survival after the implementation of the LIFE measures could be related to a decline in poisoning. At the beginning of the study, one out of every four recovered carcasses belonged to poisoned adults, whereas only two poisoned adults were found in the entire post-LIFE period. While mass wildlife poisoning events simultaneously involving several Egyptian vultures and/or other scavenger species were common before LIFE implementation (six cases recorded), no further events were detected after 2007. Therefore, we are confident that the large number of cases of unknown cause of death does not conceal a significant proportion of poisoning events and hence, the mitigation of this mortality source has been effective. The species was probably not the target of illegal poisoned baits (typically set for feral dogs and ravens on the Canary Islands), but an indirect victim of secondary poisoning, as has been described in other regions (Berny et al., 2015; Hernández \& Margalida, 2009; Ogada et al., 2012). In this respect, environmental education can be a powerful tool to mitigate human-wildlife conflicts (Cailly Arnulphi, Lambertucci, \& Borghi, 2017; Jacobson, McDuff, \& Monroe, 2006; Trewhella et al., 2004). Unfortunately, analyses of the effectiveness of this approach, 
TAB LE 1 Absolute numbers and percentages of individuals found dead by different causes of mortality and age class before and after the implementation of LIFE management actions. Electrocution, collision and entanglement are all power line accidents

\begin{tabular}{|c|c|c|c|c|c|c|c|c|}
\hline \multicolumn{5}{|c|}{ Before LIFE implementation (1998-2006) } & \multicolumn{4}{|c|}{ After LIFE implementation (2007-2017) } \\
\hline Electrocution & $2(4.1)$ & $0(0)$ & $0(0)$ & $2(4.1)$ & $2(5.1)$ & 7 (17.9) & $4(10.3)$ & $13(33.3)$ \\
\hline Collision & $0(0)$ & $3(6.1)$ & $2(4.1)$ & $5(10.2)$ & $0(0)$ & $0(0)$ & $0(0)$ & $0(0)$ \\
\hline Entanglement & $2(4.1)$ & $5(10.2)$ & $0(0)$ & $7(14.3)$ & $0(0)$ & $0(0)$ & $0(0)$ & $0(0)$ \\
\hline Poisoning & $2(4.1)$ & $5(10.2)$ & $14(28.6)$ & $21(42.9)$ & $0(0)$ & $1(2.6)$ & $2(5.1)$ & $3(7.7)$ \\
\hline Unknown & $3(6.1)$ & $3(6.1)$ & $5(10.2)$ & $11(22.4)$ & $3(7.7)$ & $5(12.8)$ & $11(28.2)$ & $19(48.7)$ \\
\hline Total & 9 (18.4) & $16(32.7)$ & $24(49)$ & 49 (100) & 5 (12.8) & $15(38.5)$ & 19 (48.7) & 39 (100) \\
\hline
\end{tabular}

Values within parentheses are expressed as percentage.

although highly useful, are often missing (Gore, 2004). In our case, actions for illegal poisoning mitigation were focused on environmental education and awareness activities targeting multiple stakeholders in Canarian society (farmers, teachers, students). Moreover, general awareness campaigns via communication media (TV, radio, newspapers, video documentaries) were focused on the visibility of the species and its conservation. In our study area, the local community - especially farmers - generally shows great esteem for the Egyptian vulture and does not perceive any conflicts with the species; rather to the contrary, they recognize its role as a provider of ecosystem services (García-Alfonso et al., 2018). This fact may have eased the awareness-raising process and contributed to the success of this strategy. In addition, in some areas the presence of wildlife monitoring groups may prevent wildlife persecution by means of winning the trust of the local community and raising awareness about the existing problems (European Commission, 2018). The monitoring team has been operating on the islands since 1998, and constantly interacting with stakeholders, which may have led to a more positive perception of the species over the years, and could have dissuaded people from using poison baits.

Casualties due to power lines became the most commonly reported mortality source after the LIFE project implementation. The vulture population shows great dependence on power lines to form communal roosts due to the total absence of woodlands on Lanzarote and Fuerteventura, which makes them highly susceptible to accidents (Donázar et al., 2002; Gangoso \& Palacios, 2002). Power line modifications apparently mitigated entanglement and collision mortality in an effective way. In contrast to the rest of the measures, anti-electrocution systems were barely implemented (see Appendix S2), which explains the lack of mitigation of electrocution as a cause of death. The substantial growth of the Egyptian vulture population during the study period could also explain the growing numbers of vultures found electrocuted in recent years. Furthermore, since roosting birds mainly concentrate along stretches of the power lines and on specific pylons (De Miguel, 2016), increased densities and behavioural interactions (e.g. fights) at these sites may promote higher electrocution rates (Lehman, Kennedy, \& Savidge, 2007). Despite huge monitoring efforts in our closed and relatively small population, our estimates indicate that we only recovered $34 \%$ of the dead marked individuals. Accidents with power lines are easier to detect due to the higher predictability of carcass location (Hernández-Matías, Real, Parés, \& Pradel, 2015), and hence, our mortality data may be biased towards power line-related mortality. Unfortunately, the small sample size of marked birds recovered that had died by different causes, or at different times or ages prevented us from using more complex multievent models to account for specific mortality and recovery probabilities associated with each cause of death. Cases of death due to unknown causes increased from $11(22.4 \%)$ to 19 (48.7\%) after LIFE implementation. Some of these birds were found in close proximity to power lines and pylons (four before LIFE and five after LIFE) and may be related to accidents with these infrastructures.

Changes in food availability are known to be an important factor shaping demographic parameters (Oro, Cam, Pradel, \& MartínezAbraín, 2004; Parra \& Tellería, 2004). Within this context, supplementary feeding has become a common tool in vulture conservation (Cortés-Avizanda et al., 2016) that mainly benefits non-breeding birds (Donázar, Margalida, \& Campión, 2009; Oro et al., 2008). In our case, the main supplementary feeding station in the centre of Fuerteventura in operation since 1998 and provided similar food amounts during the entire study period (see Appendix S2). In 2008, as an additional LIFE measure, a new supplementary feeding station was created in northern Fuerteventura, and it gathered the carcasses that were previously deposited near the neighboring farms. This feeding station shows a much lower degree of use (Van Overveld et al., 2018). Moreover, livestock numbers have decreased during the last years (see Appendix S2). Consequently, we think that supplementary feeding or changes in food availability per se cannot explain the substantial improvement of survival after LIFE implementation (see details in Appendix S2), and besides, our results indicate that the change in survival occurred in 2006, not after 2008 , when the new supplementary feeding station was created. Indeed, the highest robustness of the model with the breaking point in 2006 with respect to those in 2004 and 2008 is in line with the fact that most LIFE project actions were implemented between mid-2005 and 2008. Thus, our results indicate that reduction of mortality due to 
poisoning and accidents with power lines occurred during the LIFE e project and not after the total deployment.

Our results identify the relevance of accounting for tag loss when estimating demographic parameters, especially for long-lived species (Arnason \& Mills, 1981; McDonald, Amstrup, \& Manly, 2003). In our case, we benefitted from a huge monitoring effort allowing the detection and modelling of ring loss. Ring loss probabilities reach alarming values in the mid-long term, to the extent that half of the rings of either type are expected to be lost 15 years after marking. Interestingly, colour-ring loss became noticeable after the sixth year of use, while metal butt-end ring loss progressively increased from the very first years. Given the high loss rates that both rings reached over time in our study, not accounting for ring loss would have implied biases in our survival estimates (Arnason \& Mills, 1981), which may have led to a misinterpretation of the effectiveness of the present LIFE measures.

\section{5 | CONCLUSIONS}

The development of the LIFE04NAT/000067 project has demonstrated the effectiveness of anti-entanglement and anti-collision modifications in power lines to mitigate associated mortality. Future conservation efforts should now focus on reducing electrocution accidents, which remain as the main known non-natural mortality factor. Identifying electrocution "mortality hotspots" and applying correction measures should be a priority for future conservation plans (Guil et al., 2011; Mañosa, 2001). Fortunately, these lines of action are the foundation of a new LIFE-Nature Project (LIFE16NAT/IT/000659) approved for the period 2017-2022 (total budget 5,084,605.00 €).

Our study highlights the importance of integrating environmental education and awareness actions into conservation plans, as they appear to be the most important factors mitigating poisoning mortality in our population. The specific features of our study may have favoured the effectiveness of this strategy: namely, two small islands, with a relatively small human population and few rural stakeholders (mainly goat farmers) involved in vulture conservation. Our experience may be exportable to similar island scenarios where avian scavengers and other threatened vertebrates are on the verge of extinction (Donázar, Gangoso, Forero, \& Juste, 2005; Hille \& Collar, 2011). In fact, it is well known that biodiversity loss and accelerated extinction rates are especially important problems on islands (Sax \& Gaines, 2008). Therefore, we urge the prioritization of investments in awareness and education campaigns.

Finally, we would like to point out the serious lack of long-term assessments of effectiveness of EU LIFE projects. Usually, the final LIFE evaluations only include short-term appraisals of technical aspects and completion of proposed tasks, but lack extended sciencebased assessments over longer periods. Providing science-based evidence of the effectiveness of conservation actions can be relevant to scientists and practitioners, but also a powerful positive reinforcement for stakeholders and decision-makers towards nature and biodiversity protection (Rose et al., 2018; Sutherland et al., 2004).

\section{ACKNOWLEDGEMENTS}

The study was funded by the projects REN 2000-1556 GLO, CGL2004-00270/BOS, CGL2009-12753-C02-02, CGL2012-40013C02-01, and CGL2015-66966-C2-1-2-R (Spanish Ministry of Economy and Competitiveness and EU/FEDER). J.A.B.-B. was partially supported by Lund University funding. A.S.-A. was supported by a "Vicenç Mut" contract (PD/003/2016, Govern Balear and European Social Funds). L.G. and T.v.O. were supported by Marie Sklodowska-Curie Fellowships (747729 "EcoEvoClim" and 659008 "SocForVul"). M.G.-A. was supported by a contract from "Programa de FPU del MECD" (FPU13/05429). Further support was provided by the Dirección General de Protección de la Naturaleza (Canarian Government), the Cabildos Insulares de Fuerteventura and Lanzarote, the Reserva de la Biosfera de Fuerteventura, Jerez Zoo, ENDESA. Between 1998 and 2018 field monitoring has been done (in chronological order) by César J Palacios, Ana Trujillano, Carmen Díez, Marcos Mallo, Sandra Sierra, Juan Ramírez, Toni Batet, Walo Moreno and Julio Roldán. We also thank Natalia Évora and David de Vera for their help as LIFE Project directors.

\section{AUTHORS' CONTRIBUTIONS}

J.A.B-B., A.S.-A. and J.A.D. conceived the study; A.S.-A. designed the methodology; M.d.L.R., L.G., T.v.O., M.G-A. and J.A.D. collected the data; J.A.B.-B. and A.S.-A. analysed the data; O.P.L. and A.S.-P. did the necropsies; J.A.B.-B., A.S.-A. and J.A.D. led the writing of the manuscript. All authors contributed critically to the drafts and gave final approval for publication.

\section{DATA ACCESSIBILITY}

Data available via the Spanish National Research Council data Repository https://doi.org/10.20350/digitalcsic/8539 (Badia-Boher et al., 2018).

\section{ORCID}

Ana Sanz-Aguilar (iD https://orcid.org/0000-0002-4177-9749

\section{REFERENCES}

Arnason, A. N., \& Mills, K. H. (1981). Bias and loss of precision due to tag loss in Jolly-Seber estimates for mark-recapture experiments. Canadian Journal of Fisheries and Aquatic Sciences, 38, 1077-1095. https://doi.org/10.1139/f81-148

Badia-Boher, J. A., Sanz-Aguilar, A., dela Riva, M., Gangoso, L., van Overveld, T., García-Alfonso, M., \& Donázar, J. A. (2018). Egyptian Vulture CR data [Dataset]. Digital CSIC Repository, https://doi. org/10.20350/digitalcsic/8539

Berny, P., Vilagines, L., Cugnasse, J. M., Mastain, O., Chollet, J. Y., Joncour, G., \& Razin, M. (2015). Vigilance poison: Illegal poisoning and lead intoxication are the main factors affecting avian scavenger survival in the Pyrenees (France). Ecotoxicology and Environmental Safety, 118, 71-82. https://doi.org/10.1016/j. ecoenv.2015.04.003 
Birdlife International. (2017). Neophron percnopterus (amended version of 2016 assessment). The IUCN Red List of Threatened Species: e.T22695180A118600142.

Birdlife International (2018). Birdlife data zone. http://datazone.birdlife. org/home

Botha, A. J., Andevski, J., Bowden, C. G. R., Gudka, M., Tavares, J., Safford, R. J., \& Williams, N. P. (2017). CMS multi-species action plan to conserve African-Eurasian vultures. CMS Raptors MOU Technical Publication No. 5. CMS Technical Series No. 35. Coordinating Unit of the CMS Raptors MOU, Abu Dhabi.

Burnham, K. P., \& Anderson, D. R. (2002). Model selection and multi-model inference: A practical information-theoretic approach. New York, NY: Springer.

Cailly Arnulphi, V. B., Lambertucci, S. A., \& Borghi, C. E. (2017). Education can improve the negative perception of a threatened long-lived scavenging bird, the Andean condor. PLoS ONE, 12, e0185278. https:// doi.org/10.1371/journal.pone.0185278

Cardoso, P., Erwin, T. L., Borges, P. A. V., \& New, T. R. (2011). The seven impediments in invertebrate conservation and how to overcome them. Biological Conservation, 144, 2647-2655. https://doi.org/10.1016/j. biocon.2011.07.024

Choquet, R., Lebreton, J. D., Gimenez, O., Reboulet, A. M., \& Pradel, R. (2009). U-CARE: Utilities for performing goodness of fit tests and manipulating CApture-REcapture data. Ecography, 32, 1071-1074. https://doi.org/10.1111/j.1600-0587.2009.05968.x

Choquet, R., Rouan, L., \& Pradel, R. (2009). Program E-surge: A software application for fitting multievent models. In D. L. Thomson, E. G. Cooch, \& M. J. Conroy (Eds.), Modeling demographic processes in marked populations (pp. 845-865). Boston, MA: Springer. https://doi. org/10.1007/978-0-387-78151-8

Cortés-Avizanda, A., Blanco, G., DeVault, T. L., Markandya, A., Virani, M. Z., Brandt, J., \& Donázar, J. A. (2016). Supplementary feeding and endangered avian scavengers: Benefits, caveats, and controversies. Frontiers in Ecology and the Environment, 14, 191-199. https://doi. org/10.1002/fee.1257

Cortés-Avizanda, A., Colomer, M. A., Margalida, A., Ceballos, O., \& Donázar, J. A. (2015). Modelling the consequences of the demise and potential recovery of a keystone-species: Wild rabbits and avian scavengers in Mediterranean landscapes. Scientific Reports, 5, 17033. https://doi.org/10.1038/srep17033

Cowen,L.,\&Schwarz,C.J.(2006).TheJolly-Sebermodelwithtagloss.Biometrics, 62, 699-705. https://doi.org/10.1111/j.1541-0420.2006.00523.x

De Magalhães, J. P., \& Costa, J. A. (2009). Database of vertebrate longevity records and their relation to other life-history traits. Journal of Evolutionary Biology, 22, 1770-1774. https://doi. $\operatorname{org} / 10.1111 / \mathrm{j} .1420-9101.2009 .01783 . x$

De Miguel, A. (2016). Roosting-site selection in the Canarian Egyptian vulture (Neophron percnopterus majorensis): Individual response patterns to supplementary feeding in an insular species. Unpublished MSc Thesis. Universidad Pablo de Olavide, Seville.

Donázar, J. A., Gangoso, L., Forero, M. G., \& Juste, J. (2005). Presence, richness and extinction of birds of prey in the Mediterranean and Macaronesian islands. Journal of Biogeography, 32, 1701-1713. https://doi.org/10.1111/j.1365-2699.2005.01294.x

Donázar, J. A., Margalida, A., \& Campión, D. (2009). Vultures, feeding stations and sanitary legislation: A conflict and its consequences from the perspective of conservation biology. San Sebastián, Spain: Sociedad de Ciencias Aranzadi.

Donázar, J. A., Palacios, C. J., Gangoso, L., Ceballos, O., Gonzáles, M. J., $\&$ Hiraldo, F. (2002). Conservation status and limiting factors in the endangered population of Egyptian vulture (Neophron percnopterus) in the Canary Islands. Biological Conservation, 107, 89-97. https://doi. org/10.1016/S0006-3207(02)00049-6

European Commission. (2011). Regulation of the European Parliament and of the Council on the establishment of a Programme for the
Environment and Climate Action (LIFE). 2011/0428 (COD). Brussels: European Commission.

European Commission. (2018). LIFE \& wildlife crime. Luxembourg: Publications Office of the European Union.

European Environmental Agency. (2010). EU 2010 biodiversity baseline. Luxembourg: European Environmental Agency.

European Environmental Agency. (2011). Landscape fragmentation in Europe. Joint EEA-FOEN report. Luxembourg: European Environmental Agency.

Ferraro, P. J., \& Pattanayak, S. K. (2006). Money for nothing? A call for empirical evaluation of biodiversity conservation investments. PLoS Biology, 4, 482-488.

Forsman, D. (2016). Flight identification of raptors of Europe, North Africa and the Middle East. London, UK: Christopher Helm.

Frederiksen, M., Lebreton, J. D., Pradel, R., Choquet, R., \& Gimenez, O. (2014). Identifying links between vital rates and environment: A toolbox for the applied ecologist. Journal of Applied Ecology, 51, 71-81. https://doi.org/10.1111/1365-2664.12172

Gangoso, L., Alvarez-Lloret, P., Rodríguez-Navarro, A. A., Mateo, R., Hiraldo, F., \& Donazar, J. A. (2009). Long-term effects of lead poisoning on bone mineralization in vultures exposed to ammunition sources. Environmental Pollution, 157, 569-574. https://doi. org/10.1016/j.envpol.2008.09.015

Gangoso, L., \& Palacios, C. J. (2002). Endangered Egyptian vulture (Neophron percnopterus) entangled in a power line ground-wire stabilizer. Journal of Raptor Research, 36, 238-239.

García-Alfonso, M., Morales-Reyes, Z., Gangoso, L., Bouten, W., Sánchez-Zapata, J. A., Serrano, D., \& Donázar, J. A. (2018). Probing into farmers' perceptions of a globally endangered ecosystem service provider. Ambio. https://doi.org/10.1007/ s13280-018-1102-3

Gore, M. L. (2004). Comparison of intervention programs designed to reduce human-bear conflict: a review of literature. Human Dimensions Research Unit Publication Series. HDRU Series 04-4. Department of Natural Resources, Cornell University, Ithaca, NY.

Graiger Hunt, W., David Wiens, J., Law, P. R., Fuller, M. R., Hunt, T. L., Driscoll, D. E., \& Jackman, R. E. (2017). Quantifying the demographic cost of human-related mortality to a raptor population. PLoS ONE, 12(2), e0172232. https://doi.org/10.1371/journal. pone. 0172232

Grande, J. M., Serrano, D., Tavecchia, G., Carrete, M., Ceballos, O., DíazDelgado, R., ... Donázar, J. A. (2009). Survival in a long-lived territorial migrant: Effects of life-history traits and ecological conditions in wintering and breeding areas. Oikos, 118, 580-590. https://doi. org/10.1111/j.1600-0706.2008.17218.x

Guil, F., Fernández-Olalla, M., Moreno-Opo, R., Mosqueda, I., Gómez, M. E., Aranda, A., ... Margalida, A. (2011). Minimising mortality in endangered raptors due to power lines: The importance of spatial aggregation to optimize the application of mitigation measures. PLoS ONE, 6, e28212. https://doi.org/10.1371/journal. pone. 0028212

Henle, K., Bauch, B., Auliya, M., Külvik, M., Pe'er, G., Schmeller, D.S., \& Framstad, E. (2013). Priorities for biodiversity monitoring in Europe: A review of supranational policies and a novel scheme for integrative prioritization. Ecological Indicators, 33, 5-18. https://doi. org/10.1016/j.ecolind.2013.03.028

Hermoso, V., Clavero, M., Villero, D., \& Brotons, L. (2017). EU's conservation efforts need more strategic investment to meet continental commitments. Conservation Letters, 10, 231-237. https://doi. org/10.1111/conl.12248

Hernández, M., \& Margalida, A. (2009). Poison-related mortality effects in the endangered Egyptian vulture (Neophron percnopterus) population in Spain. European Journal of Wildlife Research, 55, 415-423. https://doi.org/10.1007/s10344-009-0255-6 
Hernández-Matías, A., Real, J., Parés, F., \& Pradel, R. (2015). Electrocution threatens the viability of populations of the endangered Bonelli's eagle (Aquila fasciata) in Southern Europe. Biological Conservation, 191, 110-116. https://doi.org/10.1016/j. biocon.2015.06.028

Hille, S. M., \& Collar, N. J. (2011). Status assessment of raptors in Cape Verde confirms a major crisis for scavengers. Oryx, 45, 217-224. https://doi.org/10.1017/S0030605310000682

Jacobson, S. K., McDuff, M., \& Monroe, M. (2006). Conservation education and outreach techniques. Oxford, UK: Oxford University Press. https://doi.org/10.1093/acprof:oso/9780198567714.001.0001

Jovani, R., \& Tella, J. L. (2005). Wear and opening as sources of band loss in the white stork. Waterbirds, 28, 426-429. https://doi. org/10.1675/1524-4695(2005)28[426:WAOASO]2.0.CO;2

Kelly, T. R., Rideout, B. A., Grantham, J., Brandt, J., Burnett, L. J., Sorenson, K. J., \& Johnson, C. K. (2015). Two decades of cumulative impacts to survivorship of endangered California condors in California. Biological Conservation, 191, 391-399. https://doi.org/10.1016/j. biocon.2015.07.012

Klaassen, R. H. G., Hake, M., Strandberg, R., Koks, B. J., Trierweiler, C., Exo, K. M., ... Alerstam, T. (2014). When and where does mortality occur in migratory birds? Direct evidence from long-term satellite tracking of raptors. Journal of Animal Ecology, 83, 176-184. https:// doi.org/10.1111/1365-2656.12135

Lebreton, J. D., Burnham, K. P., Clobert, J., \& Anderson, D. R. (1992). Modeling survival and testing biological hypotheses using marked animals: A unified approach with case studies. Ecological Monographs, 62, 67-118. https://doi.org/10.2307/2937171

Lehman, R. N., Kennedy, P. L., \& Savidge, J. A. (2007). The state of the art in raptor electrocution research: A global review. Biological Conservation, 136, 159-174. https://doi.org/10.1016/j. biocon.2006.09.015

Lieury, N., Gallardo, M., Ponchon, C., Besnard, A., \& Millon, A. (2015). Relative contribution of local demography and immigration in the recovery of a geographically-isolated population of the endangered Egyptian vulture. Biological Conservation, 191, 349-356. https://doi. org/10.1016/j.biocon.2015.07.008

Mañosa, S. (2001). Strategies to identify dangerous electricity pylons for birds. Biodiversity and Conservation, 10, 1997-2012.

Martín, A. (1987). Atlas de las Aves Nidificantes en la Isla de Tenerife (Monografía XXXII). Santa Cruz de Tenerife: Instituto de Estudios Canarios.

McDonald, T. L., Amstrup, S. C., \& Manly, B. F. J. (2003). Tag loss can bias Jolly-Seber capture-recapture estimates. Wildlife Society Bulletin, 31, 814-822.

McNamara, J. M., \& Houston, A. I. (1996). State-dependent life histories. Nature, 380, 215-221. https://doi.org/10.1038/380215a0

Morris, W. F., \& Doak, D. F. (2002). Quantitative conservation biology. Theory and practice of population viability analysis. Sunderland, MA: Sinauer Associates.

Nichols, J. D., \& Hines, J. E. (1993). Survival rate estimation in the presence of tag loss using joint analysis of capture-recapture and resighting data. In J. D. Lebreton \& P. North (Eds.), Marked individuals in the study of bird populations (pp. 229-243). Basel: Birkhäuser Verlag.

Ogada, D. L., Keesing, F., \& Virani, M. Z. (2012). Dropping dead: Causes and consequences of vulture population declines worldwide. Annals of the New York Academy of Sciences, 1249, 57-71. https://doi. org/10.1111/j.1749-6632.2011.06293.x

Oppel, S., Dobrev, V., Arkumarev, V., Saravia, V., Bounas, A., Kret, E., .. Nikolov, S. C. (2016). Assessing the effectiveness of intensive conservation actions: Does guarding and feeding increase productivity and survival of Egyptian Vultures in the Balkans? Biological Conservation, 198, 157-164. https://doi.org/10.1016/j.biocon.2016.04.002
Oro, D., Cam, E., Pradel, R., \& Martínez-Abraín, A. (2004). Influence of food availability on demography and local population dynamics in a long-lived seabird. Proceedings of the Royal Society of London B, 271, 387-396. https://doi.org/10.1098/rspb.2003.2609

Oro, D., Margalida, A., Carrete, M., Heredia, R., \& Donázar, J. A. (2008). Testing the goodness of supplementary feeding to enhance population viability in an endangered vulture. PLoS ONE, 3, e4084. https:// doi.org/10.1371/journal.pone.0004084

Palacios, C. J. (2004). Alimoche canario, Neophron percnopterus majorensis. In A. Madroño, C. González \& J. C. Atienza (Eds.), Libro Rojo de las Aves de España. Madrid, Spain: Dirección General para la Biodiversidad - SEO/BirdLife.

Parra, J., \& Tellería, J. L. (2004). The increase in the Spanish population of Griffon Vulture Gyps fulvus during 1989-1999: Effects of food and nest site availability. Bird Conservation International, 14, 33-41.

Pradel, R. (2005). Multievent: An extension of multistate capturerecapture models to uncertain states. Biometrics, 61, 442-447. https://doi.org/10.1111/j.1541-0420.2005.00318.x

Pradel, R., Gimenez, O., \& Lebreton, J. D. (2005). Principles and interest of GOF tests for multistate capture-recapture models. Animal Biodiversity and Conservation, 28, 189-204.

Pullin, A. S., Knight, T. M., Stone, D. A., \& Charman, K. (2004). Do conservation managers use scientific evidence to support their decision-making? Biological Conservation, 119, 245-252. https://doi. org/10.1016/j.biocon.2003.11.007

Rose, D. C., Sutherland, W. J., Amano, T., González-Varo, J.P., Robertson, R. J., Simmons, B. I., ... Mukherjee, N. (2018). The major barriers to evidenceinformed conservation policy and possible solutions. Conservation Letters, 2018, e12564. https://doi.org/10.1111/conl.12564

Saether, B. E., \& Bakke, Ø. (2000). Avian life history variation and contribution of demographic traits to the population growth rate. Ecology, 81, 642-653. https://doi.org/10.2307/177366

Sanz-Aguilar, A., Cortés-Avizanda, A., Serrano, D., Blanco, G., Ceballos, O., Grande, J. M., ... Donázar, J. A. (2017). Sex-and age-dependent patterns of survival and breeding success in a long-lived endangered avian scavenger. Scientific Reports, 7, 40204. https://doi. org/10.1038/srep40204

Sanz-Aguilar, A., De Pablo, F., \& Donázar, J. A. (2015). Age-dependent survival of island vs. mainland populations of two avian scavengers: Delving into migration costs. Oecologia, 179, 405-414. https://doi. org/10.1007/s00442-015-3355-x

Sanz-Aguilar, A., Martínez-Abraín, A., Tavecchia, G., Mínguez, E., \& Oro, D. (2009). Evidence-based culling of a facultative predator: Efficacy and efficiency components. Biological Conservation, 142, 424-431. https://doi.org/10.1016/j.biocon.2008.11.004

Sanz-Aguilar, A., Sánchez-Zapata, J. A., Carrete, M., Benítez, J. R., Ávila, E., Arenas, R., \& Donázar, J. A. (2015). Action on multiple fronts, illegal poisoning and wind farm planning, is required to reverse the decline of the Egyptian vulture in southern Spain. Biological Conservation, 187, 10-18. https://doi.org/10.1016/j. biocon.2015.03.029

Sax, D. F., \& Gaines, S. D. (2008). Species invasions and extinction: The future of native biodiversity on islands. Proceedings of the National Academy of Sciences of the United States of America, 105, 1149011497. https://doi.org/10.1073/pnas.0802290105

Sergio, F., Tanferna, A., De Stephanis, R., López-Jiménez, L., Blas, J., Tavecchia, G., ... Hiraldo, F. (2014). Individual improvements and selective mortality shape lifelong migratory performance. Nature, 515, 410-413. https://doi.org/10.1038/nature13696

Sergio, F., Tavecchia, G., Blas, J., López, L., Tanferna, A., \& Hiraldo, F. (2011). Variation in age-structured vital rates of a long-lived raptor: Implications for population growth. Basic and Applied Ecology, 12, 107-115. https://doi.org/10.1016/j. baae.2010.11.004 
Sutherland, W. J., Pullin, A. S., Dolman, P. M., \& Knight, T. M. (2004). The need for evidence-based conservation. Trends in Ecology and Evolution, 19, 305-308. https://doi.org/10.1016/j. tree.2004.03.018

Trewhella, W., Rodriguez-Clark, K. M., Corp, N., Entwistle, A., Garrett, S. R. T., Granek, E., ... Whitman, K. (2004). Environmental education programmes as conservation tools: Lessons from the conservation of critically engangered fruit bats in the western Indian Ocean. Conservation Biology, 19, 75-85.

Van Overveld, T., García-Alfonso, M., Dingemanse, N. J., Bouten, W., Gangoso, L., de la Riva, M., ... Donazar, J. A. (2018). Food predictability and social status drive individual resource specializations in a territorial vulture. Scientific Reports, 8, 15155. https://doi.org/10.1038/ s41598-018-33564-y

Williams, B. K., Nichols, J. D., \& Conroy, M. J. (2002). Analysis and management of animal populations. San Diego, CA: Academic Press.

\section{SUPPORTING INFORMATION}

Additional supporting information may be found online in the Supporting Information section at the end of the article.

How to cite this article: Badia-Boher JA, Sanz-Aguilar A, de la Riva M, et al. Evaluating European LIFE conservation projects: Improvements in survival of an endangered vulture. J Appl Ecol. 2019;56:1210-1219. https://doi.org/10.1111/13652664.13350 